\title{
PENGARUH KEPEMIMPINAN TRANSFORMASIONAL \\ DAN BUDAYA ORGANISASI TERHADAP PERILAKU INOVATIF KARYAWAN \\ (STUDI KASUS DI PT. BANK DANAMON INDONESIA)
}

\author{
Ryani Dhyan Parashakti, Mochamad Rizki, Lisnatiawati Saragih \\ Fakultas Ekonomi dan Bisnis, Universitas Mercu Buana \\ E-mail: ryaniparasakti@gmail.com
}

\begin{abstract}
This study aims to analyze the impact of Transformational Leadership and Organizational Culture into Innovative Behaviour in PT Bank Danamon Indonesia. Sample data were taken from questionaires that were distributed among employees of PT Bank Danamon Indonesia. Data were analysed with structural equation modeling (SEM). The result shows that transformational leadership and organisational culture have signficant impact toward innovative behavior in PT Bank Danamon Indonesia. It is advisable that further research might use more in depth information in order to have more comprehensive and significant information. The results of the t-test results of all the variables that affect the innovation, companies can improve organizational culture with a characteristic which is upheld by the organization and become a role model for the organization. Transformational leadership is concerned with the interests shared by explaining the importance of the company's goals so that members willing to subordinate his personal interests. In terms of internal and external situation of the organization, transformational used in terms of strategic and not raw.
\end{abstract}

Key words : leadership, transformational leadership, organizational culture, innovative behaviour, structure equation modelling

\section{PENDAHULUAN}

Danamon telah berada di jajaran terdepan perusahaan-perusahaan yang menginvestasikan sumber dayanya untuk kemajuan teknologi. Inovasi adalah proses membuat perubahan dari sesuatu yang sudah ada dengan memperkenalkan sesuatu yang baru. O'Sullivan (2007:5).

Perilaku inovatif karyawan di PT Bank Danamon Indonesia dapat tercermin dari sedikitnya prosedur, kebijakan, dan peraturan perusahaan yang dihasilkan. Prosedur, kebijakan, dan peraturan perusahaan tersebut bahkan banyak yang sudah lebih dari 10 tahun tidak di revisi. Prosedur, kebijakan dan peraturan perusahaan merupakan tolok ukur perilaku inovatif di perusahaan karena dengan ini kita melihat adanya ide yang mengalir dan diimplementasikan di dalam perusahaan. Apabila prosedur, kebijakan dan peraturan perusahaan yang ada di perusahaan jumlahnya sedikit dan sudah lama sekali tidak 


\section{Ryani Dhyan Parashakti \\ Mochamad Rizki \\ Lisnatiawati Saragih}

diperbaharui, ini mengindikasikan bahwa orang-orang di dalam perusahaan tersebut cenderung stagnan dan tidak mengikuti perkembangan terbaru (up to date).

Inovasi di dalam organisasi tidak bisa dilepaskan dari peran pemimpin di organisasi tersebut. Gaya kepemimpinan (leadership) sangatlah berpengaruh dalam menyuburkan perilaku inovatif karyawannya. Pemimpin di PT Bank Danamon Indonesia (kecuali Presiden Direktur) hampir seluruhnya diangkat dari karyawan yang mempunyai masa kerja sangat panjang, lebih dari 20 tahun.Seperti sebagian besar perusahaan Jepang, senioritas juga menjadi hal yang diperhitungkan di PT Bank Danamon Indonesia. Perusahaan sangat menghargai masa kerja karyawan, sehingga mereka yang telah bekerja lama akan diberi reward berupa posisi manajerial dimana mereka harus mengelola sebuah tim.

Tabel 1.1.Masa Kerja Karyawan

\begin{tabular}{ccccc}
\hline \multirow{2}{*}{ No } & \multirow{2}{*}{ Masa Kerja } & \multicolumn{2}{c}{ Jumlah } & \multirow{2}{*}{ Total } \\
\cline { 3 - 4 } & & Pria & Wanita & \\
\hline 1 & $0-3$ months & 6 & & 6 \\
2 & $>3$ mths - 1 year & 21 & 7 & 28 \\
3 & $>1$ yr - 3 yrs & 32 & 9 & 41 \\
4 & $>3$ yrs - 6 yrs & 31 & 4 & 35 \\
5 & $>6$ yrs - 9 yrs & 28 & 16 & 44 \\
6 & $>9$ yrs - 12 yrs & 10 & 4 & 14 \\
7 & $>12$ yrs - 15 yrs & 2 & 2 & 4 \\
8 & $>15$ yrs - 18 yrs & 18 & 3 & 21 \\
9 & $>18$ yrs - 21 yrs & 16 & 3 & 19 \\
10 & $>21$ yrs - 24 yrs & 15 & 1 & 16 \\
11 & $>24$ yrs & & 1 & 1 \\
& TOTAL & $\mathbf{1 7 9}$ & $\mathbf{5 0}$ & $\mathbf{2 2 9}$
\end{tabular}

Sumber : Data Personalia PT Bank Danamon Indonesia Indonesia (2015)

Data masa kerja karyawan di PT Bank Danamon Indonesia di Tabel 1.1 dapat terlihat bahwa banyak karyawan yang telah bekerja lebih dari 6 tahun. Sebagian dari mereka yang sudah mempunyai masa kerja panjang ini menduduki posisi manajerial (Senior Manager s/d General Manager). Memang mereka mempunyai kapabilitas teknikal yang sangat kuat, namun perusahaan sepertinya lalai untuk membekali kemampuan kepemimpinan (leadership) bagi mereka. Tidak adanya ketrampilan kepemimpinan (leadership) ini dapat menjadi hambatan bagi tim untuk berkinerja dengan baik. Mereka mempunyai gaya kepemimpinan yang berbeda satu dengan yang lain. Sebagian besar pemimpin yang memiliki gaya kepemimpinan transaksional namun ada juga yang memiliki gaya kepemimpinan transformasional.

Pemimpin transformasional mengharapkan para bawahannya untuk menantang status quo dan mencoba pendekatan-pendekatan baru yang lebih baik di dalam kehidupan mereka. Wang \& Rode (2011:1108). Mereka juga menekankan pada kontribusi bawahan terhadap organisasi, sehingga memotivasi bawahan untuk mengembangkan dan menawarkan ideide lebih banyak lagi untuk keberhasilan organisasi. Wang \& Rode (2011:1108). 
Tabel 1.1 mengenai data masa kerja mengindikasikan bahwa senioritas dan loyalitas di PT Bank Danamon Indonesia sangat diperhatikan, penulis berkesimpulan bahwa budaya organisasi di perusahaan tersebut lebih dominan adalah budaya clan. Cameron \& Quin (2006:42-43) menyatakan bahwa sebagian besar perusahaan Jepang mempunyai dominasi pada budaya clan dan ciri dari budaya clan ini adalah memegang teguh loyalitas dan tradisi.

Inovasi adalah proses membuat perubahan dari sesuatu yang sudah ada dengan memperkenalkan sesuatu yang baru. O'Sullivan (2007:5).Dalam hal ini Danamon telah menciptakan produk-produk baru agar dapat bersaing dengan competitor. Salah satu produk inovatif yang telah didihasilkan oleh Danam,on adalah tabubungan Danamon lebih yang mengutamakn bebas biaya administrasi tabungan dan biaya transfer.

Berdasarkan uraian latar belakang yang sudah dikemukakan sebelumnya, maka masalah penelitian ini dapat dirumuskan sebagai berikut: (1) Apakah kepemimpinan transformasional berpengaruh secara signifikan terhadapPerilaku Inovatif?; (2) Apakah budaya organisasi berpengaruh secara signifikan terhadap perilaku inovatif karyawan di perusahaan?

Tujuan penelitian ini adalah untuk: (1) Menganalisis dan mengetahui pengaruh kepemimpinan transformasional terhadap Perilaku Inovatif; (2) Menganalisis dan mengetahui pengaruh budaya organisasi terhadap perilaku inovatif karyawan di perusahaan.

\section{KERANGKA TEORITIS DAN PENGEMBANGAN HIPOTESIS Kepemimpinan Transformasional}

Kepemimpinan adalah kemampuan untuk mempengaruhi sekelompok orang untuk mencapai suatu tujuan.Robbins (2013:368).Sumber pengaruh ini dapat dari formal maupun informal karena pimpinan puncak memberikan kekuatan manajerial kepada seseorang.Kepemimpinan (leadership) muncul ketika ketika bawahan (followers) terpengaruh untuk melakukan apa yang etis dan bermanfaat bagi organisasi dan bagi mereka sendiri. Lussier \& Achua (2010:8). Organisasi memerlukan pemimpin yang kuat dan manajemen yang kuat pula untuk memastikan keefektifan organisasi.Robbins (2013).Menurut Yukl (2010) kepemimpinan adalah proses memberikan tujuan (arahan yang berarti) ke usaha kolektif, yang menyebabkan adanya usaha yang dikeluarkan untuk mencapai tujuan. Menurut Ritawati (2013) kepemimpinan merupakan salah satu faktor penentu keberhasilan organisasi. Seorang pemimpin adalah orang yang bergerak lebih awal, berjalan di depan, mengambil langkah pertama, berbuat paling dulu, memelopori, mengarahkan pikiran-pendapat-tindakan orang lain, membimbing, menuntun, menggerakan orang lain melalui pengaruhnya. Pendekatan situasional disadari bahwa tidak ada satupun gaya kepemimpinan yang terbaik dan berlaku universal untuk segala situasi dan lingkungan Ritawati (2013).

Seorang pemimpin, dapat memilih jenis gaya kepemimpinan yang tepat sesuai dengan tujuan yang dicapai pemimpin dalam organisasi yang dipimpinnya. Ada beberapa tipe kepemimpinan yang masing-masing memiliki karakter tersendiri seperti pemimpin atribusi 


\section{Ryani Dhyan Parashakti \\ Mochamad Rizki \\ Lisnatiawati Saragih}

yang mengemukakan bahwa pemimpin semata-mata suatu atribusi yang dibuat orang bagi individu-individu lain, pemimpin karismatik yang menyatakan bahwa para pengikutnya membuat atribusi dari kemampuan pemimpin yang heroik atau luar biasa, pemimpin otokratik, dan pemimpin transformasional. Kepemimpinan transformasional akhir-akhir ini semakin banyak dibicarakan orang dan tipe kepemimpinan inilah yang menjadi salah satu variabel dalam penelitian ini. Kepemimpinan transformasional merupakan upaya memotivasi karyawan untuk bekerja demi tercapai sasaran organisasi dan memuaskan kebutuhan mereka pada tingkat lebih tinggi.Putra (2015) melihat kepemimpinan transformasional yang mampu diterapkan dengan baik oleh pimpinan perusahaan akan memberikan motivasi bagi karyawan, sehingga tercapai rasa kepuasan dalam bekerja, yang semua hal ini akan memberi dampak positif terhadap kinerja karyawan dalam mengambil tanggung jawab untuk kepentingan perusahaan Pemimpin transformasional menginsiprasi bawahan untuk lebih meningkatkan kepentingan mereka untuk kebaikan organisasi dan mempunyai pengaruh yang luar biasa terhadap bawahannya. Robbins (2013).

\section{Budaya Organisasi}

Stanislavov dan Ivanov (2014) mencoba membawa budaya organisasi agar selaras dengan strategi, oleh karena itu mereka memaparkan konsep "The Cultural Web" untuk memetakan budaya organisasi. Budaya organisasi merupakan keberadaan asumsi dan perilaku di dalam organisasi yang terurai dalam enam elemen: cerita-cerita, simbol-simbol, ritual-ritual dan rutinitas, sistem pengendalian, struktur kekuasaan dan struktur organisasi.

Asumsi dasar tersebut telah terbukti dapat diterapkan dengan baik untuk menyelesaikan masalah yang dihadapi dan dianggap valid. Oleh karena itu, hal tersebut diajarkan kepada anggota baru sebagai cara yang tepat untuk mempersepsikan, berpikir dan memiliki pemahaman yang kuat dalam hubungan permasalahan tersebut.

Budaya yang ada di suatu organisasi sangat besar pengaruhnya terhadap pembentukan pribadi yang berada di dalam organisasi tersebut. Artinya, apabila budaya di organisasi tidak menyokong tumbuhnya kreativitas orang-orang di dalam organisasi tersebut, maka niscaya kreativitas orang-orang itu akan beku dan kemungkinan besar susah dikembangkan apabila dia sudah tidak berada lagi di dalam organisasi tersebut.

Pada tahun 2005 Cameron dan Quinn menghadirkan Organizational Culture Assessment Instrument (OCAI) untuk menilai budaya organisasi dengan menggunakan kuesioner.OCAl adalah kuesioner instrumen dari Competing Values Framework (CVF).CVF awalnya diciptakan sebagai kriteria untuk keefektifan organisasi yang terdiri dari tiga dimensi.Dimensi pertama, garis horizontal, membagi fokus organisasi dengan membandingkan orientasi internal dan orientasi eksternal.Dimensi kedua, garis vertical, terdiri dari pilihan organisasi terhadap stabilitas dan kontrol dibandingkan dengan fleksibilitas dan perubahan. Dimensi ketiga membandingkan proses dengan hasil akhir. Namun, didalam OCAl tidak menggunakan dimensi ketiga ini dan oleh karenanya OCAl hanya mempunyai dua dimensi : internal vs eksternal dan fleksibilitas vs stabilitas. Cameron \& Quinn (2006:34).

OCAl membagi dua dimensi itu menjadi empat kuadran.Cameron and Quinn (2006:35) menamakan masing-masing kuadran ini sebagai budaya clan, adhocracy, market dan 
hyrarchy.Kategori budaya ini diilustrasikan dalam Figur 1, dengan kategorisasi singkat di tiaptiap tipe budaya. Budaya hirarki (hyrarchy) menekankan pada koordinasi formal, pengambilan keputusan dan otoritas yang terpusat. Budaya ini menekankan stabilitas. Keras, ketepatan, tidak berubah, rapi dan bersih dapat digunakan untuk menggambarkan budaya hirarki ini. Budaya pasar (market) menekankan produktivitas, efisiensi, hasil yang terukur dan sasaran yang jelas. Budaya adokrasi (adhocracy) menekankan pertumbuhan, inovasi, flexibilitas, pengambilan resiko, komitmen dan modern. Budaya adokrasi menciptakan tempat kerja yang kreatif, dinamis dan bernuansa enterpreneur. Inisiatif individu dan kebebasan mereka dihargai. Budaya klan (clan) atau kadang juga disebut budaya kelompok, merupakan tempat yang menyenangkan dimana orang bisa banyak berbagi. Partisipasi yang luas, kerja sama tim, konsensus, pengambilan keputusan yang tidak terpusat (desentralized) dan kesetiaan merupakan bagian dari budaya klan ini.

\section{Perilaku Inovatif}

Proses inovasi di dalam pekerjaan bisa dari ide baru yang dibuat sendiri maupun yang didapat dari karyawan atau mitra bisnis, teman dan para manajer. Kemudian ada proses untuk mengkomunikasikan ide tersebut kepada orang lain. Jika ide tersebut dapat dilaksanakan dan disetujui maka tahap persiapan implementasi bisa dilakukan.

Meskipun para ilmuan dan praktisi menekankan pentingnya perilaku inovatif di tempat kerja (innovative work behaviour/IWB), pengukuran mengenai perilaku inovatif tersebut masih sangat sulit untuk dilakukan. De Jong dan Hartog (2008:6) memaparkan empat (4) dimensi untuk pengukuran perilaku inovatif di tempat kerja (IWB) yaitu : opportunity exploration, idea generation, championing dan application.

Teori inovasi sering kali menekankan bahwa inovasi lebih luas dari kreativitas dan di dalamnya termasuk implementasi dari ide-ide yang dibuat. Oleh karena itu de Jong dan Hartog mengembangkan IWB ini tidak hanya memaparkan masalah bagaimana menghasilkan ide tetapi juga perilaku yang dibutuhkan untuk implementasi ide-ide tersebut yang dapat meningkatkan kinerja individu maupun organisasi. De Jong \& Hartog (2008:5) mendefinisikan perilaku inovatif di tempat kerja / Innovative Work Behaviour (IWB) sebagai perilaku individu yang bertujuan untuk mencapai tahap pengenalan atau berusaha mengenalkan (didalam pekerjaan, kelompok atau organisasi) ide-ide, proses-proses, produk-produk atau prosedur-prosedur yang baru dan berguna. Oleh karena itu pengukuran IWB yang mereka kembangkan mencakup baik tahap pengenalan dan implementasi ide-ide kreatif tersebut.

Awal dari proses inovasi seringkali ditentukan oleh kesempatan: menemukan sebuah peluang, masalah yang muncul atau teka-teki yang perlu dipecahkan. Eksplorasi peluang termasuk adalah mencari cara untuk meningkatkan pelayanan atau proses pengiriman saat ini atau mencoba untuk memikirkan proses kerja, produk atau pelayanan dengan cara alternatif.

Idea generation merupakan elemen berikutnya dari IWB dan merupakan tahap pertama dalam mengekploitasi peluang. Untuk dapat berinovasi, selain mengetahui adanya peluang/kesempatan, kemampuan untuk membangun cara-cara baru untuk memanfaatkan peluang itu juga penting. Idea generation merujuk pada pembuatan 


\section{Ryani Dhyan Parashakti \\ Mochamad Rizki \\ Lisnatiawati Saragih}

konsep untuk tujuan peningkatan. Ide-ide yang dihasilkan dapat berkaitan dengan produk, pelayanan atau proses baru, masuk ke pasar baru, peningkatan dalam proses kerja saat ini, atau secara umum adalah solusi terhadap problem-problem yang telah diidentifikasi.

Championing aspek penting lainnya ketika suatu ide telah dihasilkan. Kebanyakan ide-ide itu perlu dijual. Koalisi sering kali dibutuhkan untuk menerapkan inovasi; ini adalah bagaimana mendapatkan kekuatan dengan menjual ide ke rekan potensial. Dalam banyak kasus, pengguna prospektif dari inovasi yang diusulkan tersebut (rekan, pemimpin, pelanggan, dII) sering merasa tidak yakin dengan nilai tambah dari inovasi tersebut. Ini memerlukan keahlian kita untuk bisa menjual dan meyakinkannya. Tahap inilah yang disebut championing, berusaha meyakinkan nilai tambah dari inovasi yang kita usulkan.

Selanjutnya ide yang telah didukung tersebut perlu diimplementasikan dan dipraktekkan. Implementasi dapat berarti meningkatkan produk atau prosedur yang telah ada, atau membangun yang baru. Usaha yang keras dan sikap yang berorientasi hasil diperlukan dari karyawan untuk mewujudkan ide tersebut. Perilaku dalam aplikasi berkaitan dengan usahausaha yang dilakukan oleh individu untuk dapat menerapkan ide tersebut ke dalam praktek nyata.

\section{Pengembangan Hipotesis}

Berdasarkan latar belakang penelitian, kajian pustaka dan kerangka pemikiran penelitian yang telah diuraikan di atas, maka hipotesis penelitian yang diajukkan sebagai berikut:

$\mathrm{H}_{1}$ : Kepemimpinan Transformasional berpengaruh signifikan terhadap Perilaku Inovatif di PT Bank Danamon Indonesia.

$\mathrm{H}_{2}$ : Budaya organisasi berpengaruh signifikan terhadap perilaku inovatif karyawan di PT Bank Danamon Indonesia.

\section{METODE PENELITIAN}

Data penelitian diambil dari kuesinoer yang dibagikan kepada karyawan PT Bank Danamon Indonesia dengan menggunakan teknik random sampling dengan jumlah sampel sebanyak 127 orang dari total populasi karyawan sejumlah 229 orang.

\section{Analisis Data}

Analisis data adalah suatu kegiatan untuk mengelompokkan, membuat suatu urutan, memanipulasi, serta menyingkat data sehingga mudah untuk dibaca dan dipahami. Silaen (2013:177). Metode yang dipilih untuk analisis data harus sesuai dengan pola penelitian dan variabel yang akan diteliti. 
Model yang digunakan dalam penelitian ini adalah model kausalitas atau hubungan pengaruh. Untuk menguji hipotesis yang akan diajukan dalam penelitian ini maka teknik analisis yang akan digunakan adalah SEM atau Structural Equation Modelling yang dioperasikan melalui program AMOS 21. Permodelan penelitian melalui SEM memungkinkan seorang peneliti dapat menjawab pertanyaan penelitian yang bersifat dimensional (yaitu mengukur apa indikator dari sebuah konsep) dan regresi (mengukur pengaruh atau derajat hubungan antara faktor yang telah diidentifikasikan dimensinya). Ferdinand (2006:6) menyatakan beberapa alasan penggunaan program SEM sebagai alat analisis adalah bahwa SEM sesuai digunakan untuk:

1. Mengkonfirmasikan unidimensionalisasi dari berbagai indikator untuk sebuah dimensi / konstruk / konsep / faktor.

2. Menguji kesesuaian / ketetapan sebuah model berdasarkan data empiris yang diteliti.

3. Menguji kesesuaian model sekaligus hubungan kausalitas antar faktor yang dibangun /diamati dalam model penelitian.

Penelitian ini menggunakan dua macam teknik analisis yaitu :

1. Analisis Faktor Konfirmatori (Confirmatory Factor Analysis). Analisis faktor konfirmasi pada SEM digunakan untuk mengkonfirmasikan faktor-faktor yang paling dominan dalam satu kelompok variabel. Pada penelitian ini analisis faktor konfirmatori digunakan untuk menguji indikator yang membentuk Kepemimpinan Transformasional, Budaya Organisasi, dan Inovasi Organisasi.

2. Regression Weight. Regression weight pada SEM digunakan untuk meneliti seberapa besar pengaruh hubungan variabel-variabel yang secara teoritis ada. Dalam penelitian ini variabel-variabelnya terdiri dari Kepemimpinan Transformasional, Budaya Organisasi, dan Inovasi Organisasi. Maka pada penelitian ini regression weight digunakan untuk menguji hipotesis $\mathrm{H} 1, \mathrm{H} 2$ dan $\mathrm{H} 3$.

\section{PEMBAHASAN Dan KESIMPULAN}

\section{Pembahasan}

\section{Uji Validitas dan Realibilitas}

Tabel 2 menunjukan nilai dari $r$ hitung dan dibandingkan dengan $r$-tabel, hasil yang diperoleh adalah semua variabel dalam penelitian ini valid. 
Tabel 2.Uji Validitas

\begin{tabular}{lrrl}
\hline & r-hitung & r-tabel & Keterangan \\
\hline Kep1 & .560 & 0.1956 & Valid \\
Kep2 & .773 & 0.1956 & Valid \\
Kep3 & .782 & 0.1956 & Valid \\
Kep4 & .645 & 0.1956 & Valid \\
Kep5 & .719 & 0.1956 & Valid \\
Budaya1 & .725 & 0.1956 & Valid \\
Budaya2 & .768 & 0.1956 & Valid \\
Budaya3 & .786 & 0.1956 & Valid \\
Budaya4 & .802 & 0.1956 & Valid \\
Innov1 & .596 & 0.1956 & Valid \\
Innov2 & .694 & 0.1956 & Valid \\
Innov3 & .766 & 0.1956 & Valid \\
Innov4 & .695 & 0.1956 & Valid \\
\hline
\end{tabular}

\section{Uji Realiabilitas}

Suharsimi Arikunto (2006) menyatakan "Reliabilitas menunjuk pada suatu pengertian bahwa sesuatu instrumen cukup dapat dipercaya untuk digunakan sebagai alat pengumpul data karena instrumen tersebut sudah baik". Reliabilitas berkenaan dengan tingkat keajegan atau ketetapan hasil pengukuran (Nana Syaodih Sukmadinata, 2009). Kuesioner dikatakan reliabel jika dapat memberikan hasil relatif sama (ajeg) pada saat dilakukan pengukuran kembali pada obyek yang berlainan pada waktu yang berbeda atau memberikan hasil yang tetap.

Uji reliabilitas dilakukan dengan rumus cronbach alpha sebagai berikut:

$$
r_{11}=\left[\frac{k}{(k-1)}\right]\left[1-\frac{\sum \sigma_{b}^{2}}{\sigma_{t}^{2}}\right]
$$

Di mana

$$
\begin{array}{ll}
\mathbf{r}_{11} & =\text { Reliabilitas instrument } \\
\mathrm{K} & =\text { banyaknya butir pertanyaan } \\
\boldsymbol{\sigma}^{2} & =\text { jumlah varians butir } \\
\boldsymbol{\sigma}^{2} & =\text { jumlah varians total }
\end{array}
$$

Apabila koefisien Cronbach Alpha $\left(r_{11}\right) \geq 0,7$ maka dapat dikatakan instrumen tersebut reliabel (Johnson \& Christensen, 2012). 
Tabel 3. Uji Realibilitas Variabel

\begin{tabular}{|c|c|c|}
\hline Variabel & Cronbach Alpha & N of Items \\
\hline Kepemimpinan & .902 & 5 \\
\cline { 2 - 3 } Transformasional \\
$\begin{array}{c}\text { Budaya Organisasi } \\
\text { Perilaku Inovatif }\end{array}$ & .916 & 4 \\
\cline { 2 - 3 } & .884 & 4 \\
\hline
\end{tabular}

Pada Tabel 3 koefisien Cronbach Alpha menunjukan nilai > 0.7 maka dapat dikatakan seluruh variabel penelitian adalah reliabel.

\section{Uji Model Measurement}

Uji model measurement adalah menguji hubungan antara indikator dengan variabel laten. Pada uji measurement model didapat hasil Chi-square sebesar 120.355, Degrees of freedom sebesar 61 dan Probability level sebesar .000 .

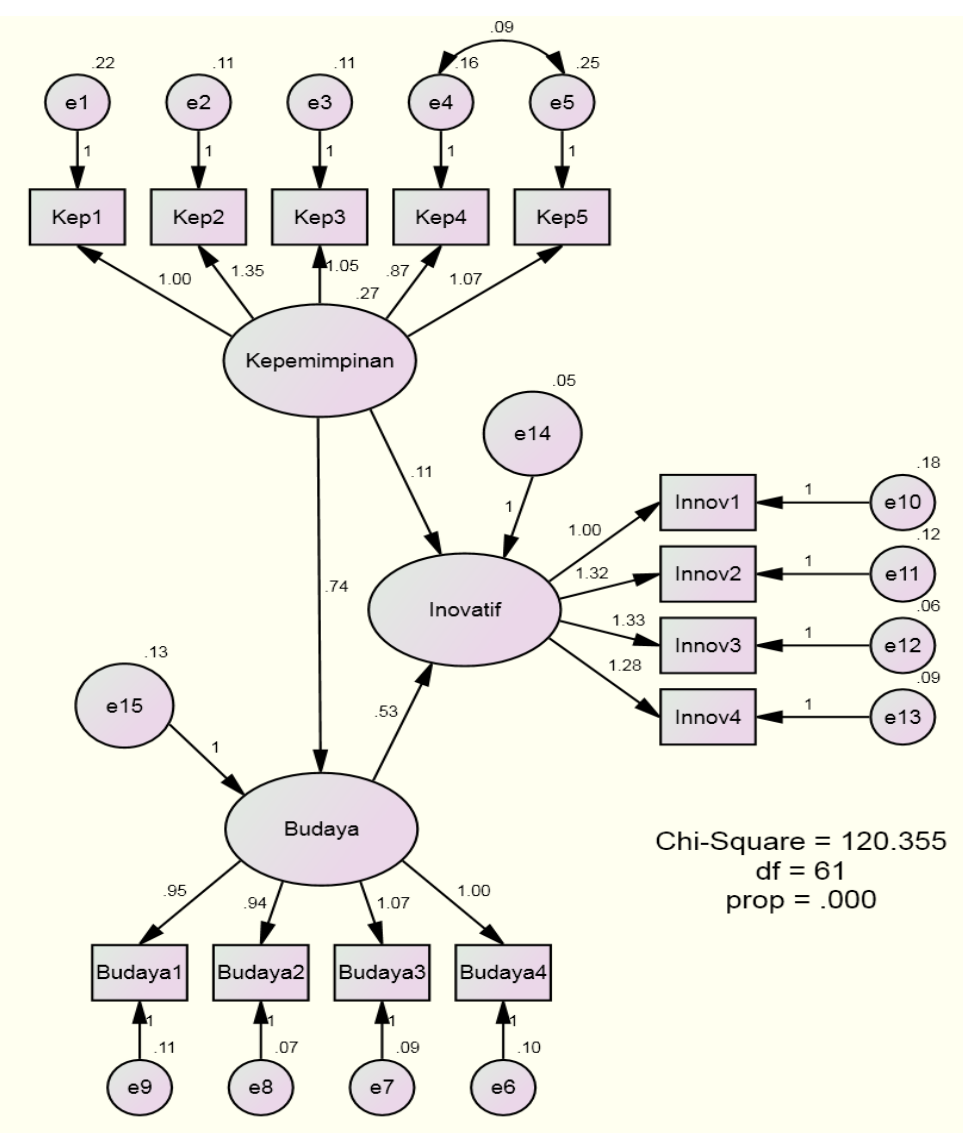

Gambar 1. Uji Struktural Model 


\section{Ryani Dhyan Parashakti \\ Mochamad Rizki \\ Lisnatiawati Saragih}

\section{Uji Normalitas Data}

Evaluasi normalitas data dilakukan dengan menggunakan nilai critical ratio skewness value sebesar \pm 2.58 pada tingkat signifikansi 0.01 (1\%). Data dikatakan berdistribusi normal jika nilai critical ratio skewness value di bawah \pm 2.58 , Ferdinand (2006).

\begin{tabular}{lrrrrrr}
\multicolumn{7}{c}{ Tabel 4 Assessment of normality } \\
\hline Variable & $\min$ & $\max$ & skew & c.r. & kurtosis & c.r. \\
\hline Innov4 & 2.330 & 4.670 & -.139 & -.569 & -.765 & -1.570 \\
Innov3 & 2.330 & 5.000 & .377 & 1.547 & -.534 & -1.096 \\
Innov2 & 2.330 & 4.670 & -.019 & -.077 & -1.005 & -2.062 \\
Innov1 & 2.330 & 5.000 & -.184 & -.754 & -1.016 & -2.085 \\
Budaya1 & 2.000 & 4.670 & -.466 & -1.912 & -.347 & -.711 \\
Budaya2 & 2.330 & 5.000 & -.418 & -1.714 & -.402 & -.824 \\
Budaya3 & 2.330 & 5.000 & .083 & .341 & -.721 & -1.480 \\
Budaya4 & 2.330 & 4.670 & -.107 & -.439 & -1.119 & -2.296 \\
Kep5 & 2.000 & 5.000 & -.036 & -.147 & -.421 & -.863 \\
Kep4 & 2.000 & 4.500 & -.343 & -1.408 & -.483 & -.991 \\
Kep3 & 2.000 & 4.500 & .101 & .414 & -.865 & -1.775 \\
Kep2 & 2.000 & 5.000 & -.084 & -.345 & -.478 & -.980 \\
Kep1 & 2.000 & 5.000 & -.187 & -.769 & .080 & .163 \\
Multivariate & & & & & 15.065 & 3.833 \\
& & & & & & \\
\hline
\end{tabular}

Berdasarkan hasil perhitungan, semua indikator nilai critical ratio skewness 3.833 lebih dari \pm 2.58 sehingga dikatakan secara multivariate dikatakan tidak normal. Tetapi bila melihat secara univariate semua nilai critical ratio skewness berada dibawah \pm 2.58 sehingga dapat dikatakan data tersebut normal secara univariate.

\section{Hasil Uji Goodness-of-fit-Model}

Tabel 5.Hasil Pengujian Goodness-of-fit model

\begin{tabular}{lllll}
\hline No & Indeks & Nilai Kritis & Hasil & Evaluasi Model \\
\hline 1 & Chi-Square & Mendekati nol & 120.355 & Buruk \\
2 & Probability level & $\geq 0.05$ & 0.000 & Buruk \\
3 & CMIN/DF & $<5.00$ & 1.973 & Baik \\
4 & CFI & $\geq 0.90$ & 0.942 & Baik \\
5 & RMSEA & $\leq 0.08$ & 0.099 & Marginal \\
6 & TLI & $\geq 0.90$ & 0.926 & Baik \\
7 & GFI & $\geq 0.90$ & 0.849 & Marginal \\
8 & AGFI & $\geq 0.90$ & 0.775 & Buruk \\
\hline
\end{tabular}

Hasil tersebut menunjukkan bahwa model yang digunakan dapat diterima. Nilai CFI menunjukkan model persamaan structural yang baik dengan nilai 0.942 , sedangkan TLI dengan nilai 0.926 adalah struktur yang baik sedangkan GFI dengan nilai 0.849 adalah nilai 
struktur yang marginal. Dari beberapa uji kelayakan model, model dikatakan layak jika paling tidak salah satu metode uji kelayakan model terpenuhi. Hair et al(2010). Dalam suatu penelitian empiris, seorang peneliti tidak dituntut untuk memenuhi semua kriteria goodness of fit, akan tetapi tergantung pada judgment masing-masing peneliti. Nilai Chi-Square dalam penelitian ini adalah 120.355. Hair et al (2010) mengatakan bahwa chi-square tidak dapat digunakan sebagai satu-satunya ukuran kecocokan keseluruhan model, karena nilai ChiSquare tidak mengindikasikan fit model dengan baik.

Ketika ukuran sampel meningkat, nilai chi-squareakan meningkat pula dan mengarah pada menolakan model meskipun nilai perbedaan antara matriks kovarian sampel dengan matrik kovarian model telah minimal atau kecil. Chi square juga berhubungan erat dengan nilai degree of freedom, bila degree of freedom lebih besar maka akan berpengaruh pada nilai Chi Square. Nilai degree of freedom dalam penelitian cukup besar yakni 61 sehingga mempengaruhi nilai chi square. Dari hasil output model pada Tabel 5 untuk kriteria uji kesesuaian model, beberapa kriteria berada pada nilai marginal. Nilai marginal adalah kondisi kesesuaian model pengukuran di bawah kriteria ukuran absolute fit maupun incremental fit, namun masih dapat diteruskan pada analisis lebih lanjut karena dekat dengan kriteria good fit. Seguro (2008) dalam Fitriyana et al, (2013:104).

\section{Modifikasi Model}

Berdasarkan pengujian kesesuaian model structural equation model yang menunjukkan adanya perbedaan secara signifikan antara matrix kovarian sample dengan matriks kovarian estimasi, maka dilakukan modifikasi atau revisi terhadap struktural model tersebut dengan mengeluarkan variabel-variabel yang tidak signifikan dari model tersebut.

Setelah dilakukan modifikasi model dan melihat dari Modification Indices, tidak ada variabel atau error yang harus diolah lebih jauh untuk dimodifikasi. Adapun hasil dari pengujian MI maupun modifikasi dari permodelan struktur, dapat dilihat pada lampiran.

\section{Uji kesesuaian model-Goodness of Fit}

Karena model persamaan struktural mengalami modifikasi, maka harus dilakukan lagi pengujian kesesuaian model untuk mengetahui apakah model modifikasi fit dengan data sample yang ada. Hasil pengujian Goodness of Fit dapat dilihat pada Tabel 6.

Tabel 6.Hasil Pengujian Goodness-of-fit Model Modifikasi

\begin{tabular}{lllll}
\hline No & Indeks & Nilai Kritis & Hasil & $\begin{array}{l}\text { Evaluasi } \\
\text { Model }\end{array}$ \\
\hline 1 & Chi-Square & Mendekati nol & 65.372 & Marginal \\
2 & Probability level & $\geq 0.05$ & 0.118 & Baik \\
3 & CMIN/DF & $<5.00$ & 1.233 & Baik \\
4 & CFI & $\geq 0.90$ & 0.988 & Baik \\
5 & RMSEA & $\leq 0.08$ & 0.048 & Baik \\
6 & TLI & $\geq 0.90$ & 0.982 & Baik \\
7 & GFI & $\geq 0.90$ & 0.912 & Baik \\
8 & AGFI & $\geq 0.90$ & 0.848 & Marginal \\
\hline
\end{tabular}




\section{Ryani Dhyan Parashakti \\ Mochamad Rizki \\ Lisnatiawati Saragih}

Tabel 6 menunjukkan bahwa nilai default model lima alat ukur (Probability Level (p), CMIN/DF,TLI, CFI, GFI dan RMSEA) semua menunjukkan angka yang cukup tinggi, yang mengindikasikan bahwa model sudah fit dengan data yang ada. Dengan demikian dapat dinyatakan bahwa pengujian ini menghasilkan konfirmasi yang baik atas dimensi-dimensi faktor serta hubungan-hubungan kausalitas antar faktor.

\section{Uji Kausalitas}

Uji kausalitas bertujuan untuk mengetahui hubungan kausalitas antara variabel eksogen dengan variabel endogen dalam suatu penelitian. Selain itu juga untuk menguji rumusan hipotesis seperti yang telah disampaikan pada bagian metodologi penelitian.Adapun hasil uji regression weight dapat dilihat pada Tabel 7.

Tabel 7. Estimasi Parameter Regression Weight Modification

\begin{tabular}{|c|c|c|c|c|c|c|c|}
\hline & & & Estimate & S.E. & C.R. & P & Labe \\
\hline Budaya & $<--$ & Kepemimpinan & .679 & .105 & 6.465 & $* * *$ & \\
\hline Inovatif & $<--$ & Kepemimpinan & .158 & .069 & 2.268 & .023 & \\
\hline Inovatif & $<--$ & Budaya & .295 & .078 & 3.781 & $* * *$ & \\
\hline Kepl & $<--$ & Kepemimpinan & 1.000 & & & & \\
\hline Kep2 & $<--$ & Kepemimpinan & 1.291 & .134 & 9.669 & $* * *$ & \\
\hline Kep3 & $<--$ & Kepemimpinan & 1.036 & .110 & 9.457 & $* * *$ & \\
\hline Kep4 & $<--$ & Kepemimpinan & .824 & .108 & 7.610 & $* * *$ & \\
\hline Kep5 & $<--$ & Kepemimpinan & .991 & .135 & 7.318 & $* * *$ & \\
\hline Budaya4 & $<--$ & Budaya & 1.000 & & & & \\
\hline Budaya3 & $<--$ & Budaya & 1.045 & .092 & 11.302 & $* * *$ & \\
\hline Budaya2 & $<--$ & Budaya & .956 & .081 & 11.763 & $* * *$ & \\
\hline Budayal & $<--$ & Budaya & .939 & .093 & 10.083 & $* * *$ & \\
\hline Innov 1 & $<--$ & Inovatif & 1.000 & & & & \\
\hline Innov2 & $<--$ & Inovatif & 1.752 & .323 & 5.416 & $* * *$ & \\
\hline Innov3 & $<--$ & Inovatif & 1.879 & .368 & 5.105 & $* * *$ & \\
\hline Innov4 & $<--$ & Inovatif & 1.780 & .356 & 5.005 & $* * *$ & \\
\hline
\end{tabular}

Hasil dari uji kausalitas menunjukkan bahwa nilai critical error tidak sama dengan nol, dan nilai $\rho<0.05$ sehingga ada hubungan yang nyata antara budaya terhadap kepemimpinan transformasional, dan ada hubungan yang nyata antara perilaku inovatif terhadap budaya organisasi, serta ada hubungan yang nyata antara perilaku inovatif terhadap kepemimpinan transformasional.

Pengujian hipotesis kausalitas yang dikembangkan dalam model ini, dapat dilihat pada Tabel 7.Pengaruh masing - masing variabel independen terhadap variabel terikat dapat dijelaskan sebagai berikut. 


\section{1) Pengujian hipotesis pertama}

Pengaruh kepemimpinan transformasional terhadap budaya perusahaan

(1) Merumuskan hipotesis

$\mathrm{H}_{0}$ : Tidak terdapat pengaruh secara signifikan variabel kepemimpinan transformasional terhadap budaya organisasi.

$\mathrm{H}_{1}$ : Terdapat pengaruh secara signifikan variabel kepemimpinan transformasional terhadap budaya organisasi.

(2) Membandingkan hasil uji output estimates dengan cut off value probabilitas. Apabila $\rho>0.05$ maka $\mathrm{HO}$ diterima. Apabila $\rho \leq 0.05$ maka $\mathrm{HO}$ ditolak

(3) Probabilitas dari kepemimpinan transformasional sebesar 0.00 yang kurang dari 0.05 sehingga $\rho(0.00)<$ cut off value (0.05), sehingga HO ditolak. Hal ini menunjukkan pada tingkat signifikansi 5 persen, kepemimpinan transformasional berpengaruh secara signifikan terhadap budaya organisasi diPT Bank Danamon.

\section{2) Pengujian hipotesis kedua}

(1) Merumuskan hipotesis

$\mathrm{H}_{0}$ : Tidak terdapat pengaruh secara signifikan variabel budaya organisasi terhadap perilaku inovatif

$\mathrm{H}_{1}$ : Terdapat pengaruh secara signifikan variabel variabel budaya organisasi terhadap perilaku inovatif

(2) Membandingkan hasil uji output estimates dengan cut off value probabilitas. Apabila $\rho>0.05$ maka $\mathrm{HO}$ diterima Apabila $\rho<0.05$ maka $\mathrm{HO}$ ditolak

(3) Probabilitas dari budaya organisasi sebesar 0.00 yang kurang dari 0.05 sehingga $\rho(0.00)$ <cut off value (0.05), sehingga HO ditolak. Hal ini menunjukkan pada tingkat signifikansi 5 persen, budaya organisasi berpengaruh secara signifikan terhadap perilaku inovatif di perusahaan.

\section{3) Pengujian hipotesis ketiga}

(1) Merumuskan hipotesis

$\mathrm{H}_{0}$ : Tidak terdapat pengaruh secara signifikan variabel kepemimpinan transformasional terhadap perilaku inovatif

$\mathrm{H}_{1}$ : Terdapat pengaruh secara signifikan variabel kepemimpinan transformasional terhadap perilaku inovatif

(2) Membandingkan hasil uji output estimates dengan cut off value probabilitas Apabila $\rho>0.05$ maka $\mathrm{HO}$ diterima Apabila $\rho<0.05$ maka $\mathrm{HO}$ ditolak

(3) Probabilitas dari kepemimpinan transformasional sebesar 0.023 kurang dari 0.05 sehingga $\rho(0.000)$ <cut off value (0.05), sehingga $\mathrm{HO}$ ditolak. Hal ini menunjukkan 


\section{Ryani Dhyan Parashakti \\ Mochamad Rizki \\ Lisnatiawati Saragih}

pada tingkat signifikansi 5 persen, kepemimpinan transformasional berpengaruh secara signifikan terhadap perilaku inovatif di perusahaan.

\section{Kesimpulan}

a. Hasil uji-† memberikan hasil bahwa semua variabel berpengaruh kepada inovasi, maka perusahaan dapat meningkatkan budaya organisasi dengan sebuah karakteristik yang dijunjung tinggi oleh organisasi dan menjadi panutan bagi organisasi.

b. Kepemimpinan transformasional mementingkan kepentingan bersama dengan menjelaskan betapa pentingnya tujuan perusahaan tersebut sehingga anggota rela mengesampingkan kepentingan pribadinya. Dalam hal situasi internal dan eksternal organisasi, transformasional dipakai dalam hal yang bersifat strategis dan tak baku.

\section{IMPLIKASI DAN KETERBATASAN}

\section{Saran}

a. Danamon menerapkan gaya kepemimpinan transformational yaitu kepemimpinan yang mampu memotivasi pengikut untuk secara lebih dari yang ada sekarang mewujudkan minat pribadinya secara segera (transcend their own immediate self interest) guna bersama-sama menerjemahkan misi dan visi organisasinya dan mampu mengubah energy sumber daya, baik manusia, instrument, maupun situasi untuk mencapai tujuan perusahaan secara menyeluruh.

b. Bank Danamon dapat memberikan pelatihan kepada pemimpin untuk memahai lebih jauh mengenai kepemimpinan yang transformasional.

c. Harapan para pemimpin Bank Danamon karyawan yang sudah mengikuti pelatihan baik dalam on the job training or in job training dapat dikembangkan dan melakukan tindakan yang profesional dan disiplin, mengupayakan terbaik, jujur, kerjasama dan peduli (nilai-nilai danamon) dalam aplikasi sehari-hari sehingga tranformasional yang diharpakan dapat berjalan dengan sempurna di lapangan untuk semua level.

\section{DAFTAR REFERENSI}

Abdi, Kambis., \& Senin, Aslan Amat. (2014) "Invesyigation on the Impact of Organizational Culture on Organization Innovation". Journal of Management Policies and Practices, June 2014, Vol. 2, pp:01-10

Bass, B.M., B.J. Avolio, D.I. Jung \& Y. Berson. (2003) "Predicting unit performance by assessing transformational and transactional leadership", Journal of Applied Psychology, Vol. 88, No. 2, pp. 207-218

Dachlan, Usman. (2014). Panduan Lengkap Structural Equation Modeling Tingkat Dasar. Lentera llmu. Jakarta.

De Jong, Jeroen P.J., \& Den Hartog, Deane N. (2008). Innovative Work Behavior: Measurement and Validation. SCALES. Zoetermeer. 
Fitriyana, Fina., Mustafid., \& Suparti. (2013)."Analisis Pengaruh Kualitas Layanan Dan Kualitas Produk Terhadap Loyalitas Pelanggan Pada Online Shop Menggunakan Structural Equation Modeling".Jurnal Gaussian, Vol. 2, No. 2, p. 98-108

Hair, Joseph F., Rolph E. Anderson, Ronald L. Tatham, and C. William.Black.(2010). Multivariate Data Analysis. Seventh Edition. Pearson. New Jersey.

Hartnell, Chad A., Ou, Amy Yi., and Kinicki, Angelo. (2011). "Organizational Culture and Organizational Effectiveness: A Meta-Analytic Investigation of the Competing Values Frameworks's Theoretical Suppositions".Journal of Applied Psychology, Vol. 96, No. 4. pp. 677-694.

Imran, Rabia., Zaheer, Arshad., \& Noreen, Umara. (2011). "Transformational Leadership as a Predictor of Innovative Work Behaviour: Moderated by Gender". World Applied Sciences Journal 14(5). pp 750-759.

Jeffrey, Ignatius., Hermawan, Aji., Hubeis, Musa., Djohar, Setiadi. (2011). "Pengaruh Kecocokan Gaya Kepemimpinan dan Budaya Organisasi terhadap Kinerja Individu: Studi Kasus PT". XYZ.Jurnal Manajemen \& Agribisnis, Vol. 8, No. 2, pp. 97-107.

Kresnandito, Andhika Putra., \& Fajrianthi. (2012). "Pengaruh Persepsi Kepemimpinan Transformasional terhadap Perilaku Inovatif Penyiar Radio".Jurnal Psikologi Industri dan Organisasi. Vol. 1, No. 02, hal. 96-103.

Losane, Loreta. (2013). "Innovation Culture - Determinant of Firms' Sustainability".International Journal of Social, Education, Economics and Management Engineering. Vol. 7, No: 10, 2013, pp. 1483-1488.

Mozaffari, Farough Amin. (2008). A Study of Relationship between Organizational Culture and Leadership. International Conference on Applied Economics - ICOAE, pp. 679-688.

Okibo, Bichanga Walter. and Shikanda, Evans Wanga. (2013). "Effects of Organizational Culture on Innovation in Services Industry: A Case Study of Postal Corporation of Kenya". European Journal of Business Management. Vol. 3, No. 3, pp. 66-85.

Putra, I Kadek Andika Pramana., \& Subudi, Made. (2015). "Pengaruh Gaya Kepemimpinan Transformasional dan Lingkungan Kerja Fisik terhadap Kinerja Karyawan PT BPR Pedungan".E-Jurnal Manajemen Unud. Vol. 4, No. 10, hal. 3146-3171.

Ritawati, Agustina. (2013). "Pengaruh Kepemimpinan Transformasional dan Budaya Organisasi terhadap Kepuasan Kerja dan Kinerja Karyawan PT. Jamsostek (Persero) Cabang Surabaya". Jurnal Ekonomi \& Manajemen, Vol. 9, No 1, hal. 82-93.

Robbins, Stephen P \& Judge, Timothy A. (2013). Organizational Behavior. Fifteenth edition. Prentice Hall. New Jersey.

Rowold, Jens. (2011). "Relationship between Leadership Behaviors and Performance. The moderating role of a work team's level of age, gender, and cultural heterogeneity". Leadership \& Organization Development Journal, Vol. 32, No. 6, pp. 628-647.

Sari, Artika Novriyana., Ulfa, Cherly Kemala. (2013). "Perilaku Inovasi Karyawan Ditinjau dari Empat Kuadran Iklim Organisasi".Jurnal PREDICARA. Vol. 2, No. 1.

Schmidt, Peter., \& Lebedeva, Nadezhda N. (2014). Values, Efficacy and Trust as Determinants of Innovative Organizational Behaviour in Russia. Working Paper Basic Research Program at the National Research University Higher School of Economics 21/PSY/2014. Moscow.

Seen, Nn Yu., Singh, Saran Kaur Garib., \& Jayasingam, Sharmila. (2012). "Organizational Culture and Innovation among Malaysian Employees".In The Journal of Human Resource and Adult Learning, Vol. 8, Num.2, Dec. 2012, pp. 147-156. 


\section{Ryani Dhyan Parashakti}

Mochamad Rizki

Lisnatiawati Saragih

Stanislavov, Ivaylo., Ivanov, Stanislav. (2014). The Role of Leadership for Shaping Organizational Culture and Building Employee Engagement in the Bulgarian Gaming Industry. Original Scientific Paper. Vol. 62. No. 1. pp. 19-40.

Stoffers, Jol., Neessen, Petra., van Dorp, Pim. (2015). Organizational Culture and Innovative Work Behavior: A Case Study of a Manufaturer of Packaging Machines. American Journal of Industrial and Business Management. Volume 5. pp. 198-207.

Wang, Peng., \& Rode, Joseph C. (2011). Transformational Leadership and Follower Creativity: The Moderating Effects of Identification with Leader and Organizational Climate. Sagepub. Ohio.

Yesil, Salih., \& Kaya, Ahmet. (2012). The Role of Organizational Culture on Innovation Capability: An Empirical Study. International Journal of Information Technology and Business Management. Vol.6, No. 1. Oct 2012, pp. 11-25.

Yildiz, Muge Leyla., \& Ozcan, Esra Dinc. (2014). Organizational Climate as a Moderator of the Relationship between Transformational Leadership and Creativity. International Journal of Business and Management. Vol. II (I). 2014, pp. 76-87.

Yukl, Gary. (2010). Kepemimpinan Dalam Organisasi. Edisi Kelima. Indeks. Jakarta. 